Another method of bonding a refractory has been already hinted at in the description of Marquardt porcelain. If a pure high-melting compound of two or more oxides be selected as the refractory, it may be made up by thoroughly mixing the component oxides in finely powdered form. The mixture is then molded in the usual way, dried and burned. At a temperature well below the melting point of the compound, the oxides will begin to unite to form the compound, and this chemical reaction will bind the mass together even more effectively than could be accomplished by sintering.

The best example of such a product is magnesium aluminate or spinel, $\mathrm{MgO} \cdot \mathrm{Al}_{2} \mathrm{O}_{3}$. It has been occasionally used by individual investigators in Germany for crucibles, tubes, and the like, and a similar mixture, probably impure, has also been made up into forms by the Royal Berlin Porcelain Works. As is shown in Fig. I, its melting point is unusually high and its eutectics with its two component oxides melt not much lower (1925 and 2030 ). Particular care need not be taken, therefore, to make it up in the exact proportion to form $\mathrm{MgO} \cdot \mathrm{Al}_{2} \mathrm{O}_{3}$. It is to be regretted that it is not yet available in this country in forms similar to those of Norton alundum.

Among the other facts represented on the diagrams of Figs. I and II, which find applications in industrial science, we may mention some of the properties of the polymorphic forms of the pure oxides. One of the diagrams of Fig. II represents the volume curves of the forms of silica. The inversion of quartz at $575^{\circ}$ is accompanied by a sudden change of rolume, an expansion in passing from the low-to the hightemperature form; so a granite wall in a burning building, if it becomes heated to $575^{\circ}$, is seriously shattered by the inversion of the quartz which makes so large a proportion of the stone. The silica brick cap of a glass furnace, as the temperature passes $575^{\circ}$, changes so rapidly in dmensions that a man must be kept at hand with a wrench to "follow up" the cap. No ordinary force is able to resist the change; a pile of 4 or 5 tons of pig iron failed to keep the cap from rising at $575^{\circ} .1$ Another practical effect is the disintegration of silica brick. Brick made of quartz is likely to be "rotted" or weakened by disintegration if heated and cooled repeatedly past the $575^{\circ}$ point.

Fused silica, or "quartz glass:" is only stable above the melting point of cristobalite $\left(1625^{\circ}\right)$. If used at temperatures below this, it strives constantly to crystallize, and the speed of crystallization is greater, the higher the temperature. Hence the well-known "devitrification" of silica glass. But it happens that the high-temperature form of cristobalite has practically the same density as the glass itself, so that if held at a high temperature the material retains its transparency and homogeneity. Only when it passes the $\alpha-\beta$ inversion point at 200 to $275^{\circ}$ does it break up into the familiar chalky, devitrified mass. Whether the cristobalite retains the strength of the glass at high temperatures I do not know, but for some purposes, at least, it might be interesting to see whether the

\footnotetext{
1 Trans, Am. Ceramic Soc, 15 (1913), 519.
}

original advantageous properties of the glass would not be preserved if the furnace were not allowed to cool below $300^{\circ}$.

In I9I4 Mr. F. J. Tone, of the Carborundum Company, sent us what seemed to be a new crystalline form of silica, consisting of a chalky mass of fine parallel fibers. The microscope showed that it was really amorphous, and was in fact a fibrous glass probably deposited from a vapor. This tendency of amorphous silica to deposit in various fibrous forms is very marked.

Crystalline alumina is now used by the hundreds of tons in grinding-wheels. The crystals are for the most part corundum or $\alpha$-alumina, but a certain proportion of $\beta$-alumina is also found in the artificial abrasives. One use of this fused alumina which is familiar to all chemists is in the Norton Company's "alundum" articles. We have observed recently that boats made of alundum are extraordinarily constant in weight at high temperatures, much more so than platinum. ${ }^{1}$ Platinum steadily loses weight in oxygen at I I00- $200^{\circ}$, especially when iron oxide is heated in it, whereas an alundum boat is constant within $0 . I \mathrm{mg}$. The reason is simple and obvious: platinum is an oxidizable metal and forms a volatile oxide, while alumina is a completely saturated and non-volatile oxide. At II00-I $200^{\circ}$ the platinum is oxidized by the oxygen of the air, and the oxide is carried. away, while the $\mathrm{Al}_{2} \mathrm{O}_{3}$ remains unchanged.

Many other facts with their practical applications could be brought out by going through the diagrams in detail, but I believe that enough has been said to show that future progress in the application of our knowledge of the common refractory oxides must follow two principal lines: (I) control of the purity of materials, and (2) accurate control of high temperatures.

$$
\begin{gathered}
\text { GEOPHYSICAL IABORATORY } \\
\text { CARNEGIE INSTITUTION OF WASHINGTON }
\end{gathered}
$$
WASHINGTON, D. C

\section{SOME EXPERIMENTS ON THE CONCENTRATION OF RADIUM IN CARNOTITE ORES}

By ALBERT G. LOOMrs AND Herman Schlundt Received June 24, 1916

The investigations ${ }^{2}$ of the United States Bureau of Mines have emphasized the fact that the carnotite deposits of Colorado and Utah constitute the principal source of radium in the United States. In recent years these ores have also become one of the main sources of the radium produced abroad. About a year ago the Standard Chemical Company published the statement ${ }^{3}$ that in the year Igr 4 it had produced 18 grams of hydrous radium bromide, equivalent to 9.6 grams of radium element, and that its total production up to March I, I9I5, had reached the handsome figure of 24.3 grams of the bromide.

1 Hostetter and Sosman, J, Am, Chem. Soc, 38 (1916), 1188-irg8

- Moore and Kithi1, "A Preliminary Report on Utanium, Radium and Vatradium," Bureau of Mines, Bull. 70 (1913); Parsons, Moore, Lind and Schaefer, "Extraction and Recovery of Radium. Uranium and Va. nadium from Carnotite," Bureau of Mines, Bull. 104 (1915).

3 Viol, "The Radium Situation in America," Radium, 4. (1915), 106 
The American carnotites consist of a sandstone with clay binder impregnated with the mineral carnotite, which is probably a hydrous potassium uranium vanadate containing barium and calcium. The valuable constituents of the ore are radium, uranium and vanadium.

The ore on the market is hand sorted and is sold on the basis of its uranium content expressed as the oxide $\mathrm{U}_{3} \mathrm{O}_{8}$. The percentage of uranium oxide generally runs between $I .5$ and 2.5 per cent, which represents a radium content of 4 to 7 parts per billion (4 to $7 \times 10^{-9} \mathrm{~g}$. radium per $\mathrm{g}$. of ore).

Until recently but little had been published on methods of treating carnotite for the extraction of radium other than a number of patents issued. Practically all of the processes patented involve the extraction of radium by direct chemical treatment. Initial concentration by mechanical means may be in use but the published results are very meager. ${ }^{1}$ While the patents describe the processes for the extraction of the valuable constituents of the ore, they afford only scant information as to the quantitative results obtainable.

The value of quantitative experiments conducted on a laboratory scale is well illustrated by the early experiments of Moore and $\mathrm{Kithil}^{2}$ in which carnotite ore was treated with concentrated hydrochloric and nitric acids. The promising results obtained in the laboratory of the Bureau of Mines have been duplicated during the past two years on a commercial scale in the plant of the National Radium Institute, in Denver. The published results by Parsons, Moore, Lind and Schaefer ${ }^{3}$ constitute by far the most comprehensive contribution to the extraction and recovery of radium, uranium and vanadium from carnotite that has appeared.

The experiments of Plum have special scientific value since they present methods of extraction and separation of the other radioactive constituents of carnotite as well as radium. Using $\mathrm{I} \mathrm{kg}$. of ore, Plum succeeded in extracting 89.9 per cent of the radium by treating successively with sodium carbonate solution, hydrochloric acid, and finally nitric acid.

The investigations of the Bureau of Mines show that equally good extractions can be obtained on a commercial scale by boiling the ore with 38 per cent nitric acid containing a small quantity of hydrochloric acid. After filtering, washing, and partially neutralizing the excess of acid, the radium is removed from the filtrate in the usual way by adding the proper quantities of barium chloride and sulfuric acid. The crude barium sulfates thus obtained generally contain about rooo parts of radium per billion. The concentration of the radium is increased $I_{50}$ to 200 times and at the same time nearly all of the uranium and about 5o per cent of the vanadium of the ore are removed.

1 Fischer outlines a method of initial concentration by grinding the ore and removing the carnotite as slime suspended in water, Met. and Chem. Eng., 10 (1912), 361

2 Bureall of Mines, Bull, 70 (1913); Loc. cit.

3 Ibid., 104 (1915); Loc. cit.

4 J. Am. Chem. Soc., $37(1915), 1797$.
Our experiments include a study of the following common reagents used in the treatment of carnotite ores with the object of concentrating the radium: (1) concentrated sulfuric acid, (2) sodium bisulfate and salt cake, (3) sulfurous acid, (4) chlorine water, (5) carbonic acid.

\section{PARTIAL ANALYSIS OF ORES}

In most of the experiments a typical low-grade ore was used containing $I .66$ per cent $\mathrm{U}_{3} \mathrm{O}_{8}, 4.03$ per cent $\mathrm{V}_{2} \mathrm{O}_{5}$, and 4.88 parts of radium per billion $(4.88 \times$ $10^{-9}$ g. radium per $\mathrm{g}$. of air-dry ore). A few experiments were conducted with a high-grade ore containing $\mathrm{I}_{4} .4$ per cent of $\mathrm{U}_{3} \mathrm{O}_{8}, 9.7$ per cent of $\mathrm{V}_{2} \mathrm{O}_{5}$, and 42.68 parts of radium per billion.

The radium values of the ores were, determined directly and are approximately 5 per cent higher than the normal equivalent quantities, 4.69 and 40.66 parts of radium, computed by multiplying the uranium content by the equilibrium ratio ${ }^{1}$ of radium to uranium $\left(3.33 \times 10^{-7}\right)$. Differences of this magnitude are not at all uncommon for small lots of ore and have been shown to occur occasionally in ton lots of well sampled ore. ${ }^{2}$

A stock of $250 \mathrm{~kg}$. of low-grade ore was available and $5 \mathrm{~kg}$. of high-grade. Both lots of ore came from the carnotite deposits in the Paradox Valley, southwestern Colorado. The low-grade ore was sampled and ground to pass a 20-mesh sieve in the plant of a commercial ore grinding and sampling firm. The high-grade ore was ground and composited with the ordinary laboratory appliances until it passed a 40mesh sieve.

The method of analysis followed in the determination of uranium and vanadium in the ores is described in Bulletin 70, U. S. Bureau of Mines, ${ }^{3}$ and by Lind and Whittemore in their investigations on the radium: uranium ratio in carnotites. ${ }^{4}$ The determination of radium in the ores and radium concentrates separated from them in the course of the experiments was conducted electroscopically by the emanation method. In assaying the ore samples the emanation was generally separated by boiling suitable quantities with nitric acid after the samples had been sealed up for a month or longer to attain equilibrium with the emanation that diffuses away continually under ordinary conditions. Proper measurements of the ionization current produced by the emanation in standardized air-tight electroscopes furnished the data required for computing the quantity of radium.

The determination of radium in the concentrates, crude sulfates, and some of the ore residues (tailings) was conducted for the most part by fusion of weighed samples with mixed carbonates of sodium and potassium followed by solution of the products in nitric acid, or a second fusion, after the lapse of a known period of storage extending over several days. The emanation that accumulates during the interval when collected quantitatively and transferred to a stand-

1 Heiman and Marckwald, Jahrb. Radioakt. u. Elektronik, 10 (1913), 299.

${ }^{2} \mathrm{Cf}$. Lind and Whittemore, J. Am. Chem. Soc., 36 (1914), 2080.

${ }^{3}$ Moore and Kithil, Bureau of Mines, Bull. 70 (1913), 88.

4 J. Am. Chem. Soc, 36 (1914), 2076. 
ardized electroscope, can be accurately determined by properly measuring the ionization current produced. From the data thus obtained the quantity of radium in the sample is readily deduced. ${ }^{1}$

In most of the experiments the approximate percentage extraction of radium from the ore was determined by comparison of the $\alpha$ radiation from equal surfaces of ore and tailings spread out in thin layers on very shallow trays. Extraction values obtained by this method always exceeded the values found by determining the radium content of the tailings by the emanation method, when sulfuric acid or salt cake were used in treating the ore.

This observation was a matter of some moment to $u s$ and materially delayed the progress of the experiments. It explains a discrepancy frequently obtained in checking up the recovery of radium. In determining the distribution of radium among the concentrates, tailings and solutions obtained in the course of an experiment, the total radium recovered generally fell short 5 per cent or more (see data 20 to 23 , Table I) when the radium content of the tailings was based upon the activity measured by the $\alpha$ radiation from films of ore and tailings of equal area, even after the latter had stood for a month. For example, an extraction of 92 per cent by the film method would generally correspond to a recovery of only 86 per cent of the radium. This discrepancy disappeared when the determination of radium in the tailings was made by the emanation method in the same way as the carnotites and crude sulfates were assayed. The extraction values were then lower, and the apparent loss. of radium was found to be present in the tailings.

At one stage of the work we searched in vain for radium losses in the solutions obtained when liquors of concentrated sulfuric acid containing barium and radium dissolved as bisulfates are diluted with water to precipitate the normal sulfates. The diluted solutions ranged in concentration from 5 to $I 5$ per cent of sulfuric acid. Determinations in this laboratory conducted by J. Underwood, on the solubility of the sulfates of the alkaline earth metals in C. P. sulfuric acid $\left(99.5\right.$ per cent $\left.\mathrm{H}_{2} \mathrm{SO}_{4}\right)$, indicate that approximately $\vec{s}$ per cent of sulfates remain dissolved when saturated solutions of the bisulfates in concentrated sulfuric acid are diluted with water. For example, after boiling concentrated sulfuric acid containing an excess of finely powdered barium sulfate for several hours to obtain a saturated solution of the bisulfate, the quantities of barium sulfate in sampies of $10 \mathrm{cc}$. each of the clear liquid were found to be $\mathrm{x} .957$ and $\mathrm{I} .850 \mathrm{~g}$., respectively. The higher value represents the residue left when the acid was expelled directly, while the lower result is the weight of barium sulfate obtained by diluting the acid with ro volumes of water. It will be noted that the direct determination is about 5 per cent higher than the

1 For details of operation, apparatus, and formulas used in the calculation of results, see among other relerences: Schlundt and Moore, J. Phys. Chem., 9 (1905), 320; Randall, Trans. Am. Electrochem. Soc., 21 (1912), 463; Lind and Whittemore, J. Am. Chem. Soc, 36 (1914), 2062-5; Schlundt, Trans. Am. Electrochem. Soc., 26 (1915), 163. value obtained by the procedure followed in recovering radium from sulfuric acid liquors.

Moreover, Lind, ${ }^{1}$ in his investigations on the determination of radium by the emanation method, points out that very erroneous results may be obtained with solutions containing no barium but an excess of a barium precipitant such as a sulfate or carbonate, which are usually solutions from a radiumbarium precipitation.

Our customary procedure of determining the small quantities of radium in the filtrates obtained from the precipitation of radium-barium sulfates by diluting concentrated sulfuric acid solutions was to boil an aliquot part of the filtrate to expel any radium emanation and then store the solution for a definite period in a sealed flask. The emanation that accumulated during the period of storage was then boiled off, collected, and transferred to an air-tight standardized electroscope and the ionization current properly measured. The values thus obtained represented only 0 . I per cent of the radium in ore samples or concentrate-a relatively small fraction of the observed discrepancy. But if radium is precipitated during the period of storage, then the emanation obtained by boiling may be far too low as the radium-barium sulfate precipitates are very low in emanating power.

To ascertain whether considerably larger quantities of radium may escape detection in the filtrates by our procedure, determinations were conducted in some other ways:

(I) A precipitate of barium sulfate was thrown down in the hot filtrate by adding $5 \mathrm{cc}$. of a 5 per cent solution of barium chloride. After standing 4 days to complete the precipitation and settling of the sulfates, the precipitate was removed, fused with mixed carbonates of sodium and potassium and the radium determined by the procedure outlined above for the assay of crude sulfates and concentrates.

(2) The sulfuric acid of the filtrates to be tested for radium was nearly neutralized with sodium hydroxide and $5 \mathrm{cc}$. of barium chloride solution added. The radium content of the precipitate of barium sulfate was then determined as in the preceding experiment.

(3) Samples of solutions obtained from some of the ore concentrates were evaporated and the free sulfuric acid expelled by heating. Radium was determined in the residues by the emanation method after fusion with mixed carbonates.

The radium values obtained by precipitating barium sulfate in the filtrates as outlined in. (I) and ( 2 ) above stood in good agreement with the low radium content of the solution as determined by the usual method followed in our experiments.

However, the radium content of the total residue obtained by evaporating the excess of sulfuric acid was found to be I. I per cent of the radium content of the ore samples and concentrates (see Tables I and II). We attribute this higher value to the presence in the filtrate of traces of precipitated radiumbarium sulfate that passed through the filter. But

1 Thrs Jovrkar, 7 (1915), 1024. 
inasmuch as the introduction into our balance sheet for radium of I.I per cent for radium losses in the solutions still left a discrepancy of nearly 5 per cent for most of the runs we then turned our attention to a more careful examination of the tailings and found there the missing radium.

In this connection we wish to point out that the presence of a relatively large amount of silica in the samples of tailings was not found to interfere in making the radium determinations provided the fused mass is pulverized before it is sealed up for the accumulation of the emanation. If the fusion is not ground up, then the acid fails to penetrate very far into the interior and the results are far too low. The values obtained by removing the silica before fusion with mixed carbonates, as suggested by Lind, ${ }^{1}$ were generally somewhat smaller than the direct determinations with silica present.

\section{TREATMENT OF ORE WITH SULFURIC ACID}

When carnotite ores are treated with sulfuric acid the uranium and vanadium compounds are converted into water-soluble form and their extraction may be made practically quantitative. In the process of Fleck, Haldane and White $^{2}$ the ore is boiled with ${ }^{5}$ to 20 per cent acid, which results in leaving the radium with the insoluble residue. The radium may be concentrated by agitating the residue with water and separating the coarse and fine materials by differential sedimentation. In this way most of the radium becomes distributed among the finely divided portion of the residue representing approximately one-tenth of the ore.

McCoy's method ${ }^{3}$ of treating carnotites involves roasting with concentrated sulfuric acid till finally a temperature of $300^{\circ}$ or even higher is reached. When the solid cake is leached with water, the soluble sulfates are removed and the radium remains with the insoluble residue from which it may be recovered by any known method, the treatment being materially simplified by the absence of vanadium, uranium and iron.

Danforth, Samuels, and Martersteck ${ }^{4}$ have devised a method for the treatment of complex refractory carnotites for the purpose of obtaining, especially, vanadium compounds. The crushed ore is first given a plain oxidizing roast at a temperature of about $600^{\circ}$, and is then treated with sulfuric acid of about $1.30 \mathrm{sp}$. gr. at $80^{\circ}$. The radium and barium which may be present in the ore remain in the residue. To extract the radium, the residue, after removal of soluble sulfates, is treated with mixed solutions of sodium hydroxide and sodium carbonate (the reagents used by Haitinger and Ulrich in working up the residues of pitchblende) to render the sulfates and silicates soluble, and to convert radium and barium compounds into carbonates. After filtering

1 This Journal, 7 (1915), 1024; Loc, cit.

2 U. S. Patent 890,584 (1908). The different methods of treating carnotite ores patented in the United States prior to 1915 are described in detail in Bureau of Mines, Bull, L04 (1915), 15-27.

${ }^{3}$ U. S. Patent $1,098,282(1914)$.

U. S. Patent 1,126,182 (19:15)

'K. K. Akad. Wissenschaft (Vienna), 117 (1908), 619. and thorough washing of the residue, the radium and barium carbonates are removed with dilute hydrochloric acid and- recovered from the filtrate by the addition of the proper quantities of sulfuric acid and barium chloride.

When carnotite is boiled with concentrated sulfuric acid in considerable excess, the radium and some of the calcium compounds present are, among others, converted into bisulfates which remain in solution in the hot acid and may then be separated from the insoluble components by filtration followed by washing the residue with concentrated sulfuric acids. From the acid liquors thus obtained the radium is recovered by diluting with water, whereby bariumradium sulfate is precipitated, and calcium sulfate ton, if the acid liquor is diluted with an equal quantity of water as proposed by Bredt, ${ }^{1}$ but a high-grade crude sulfate relatively low in calcium can be obtained directly by diluting the acid liquor with at least Io times the bulk of water, as outlined by Schlundt. ${ }^{2}$

When the valuable constituents of the ore-radium, vanadium and uranium-are removed with concentrated sulfuric acid by a single stroke, it is necessary to use about 3 times as much acid as ore. ${ }^{3}$ A considerable saving of acid can be effected by conducting the concentration of radium in steps that finally yield crude stlfates of equally good quality. The method involves: (I) digestion or roasting of the ore with a sufficient quantity of concentrated acid to convert the iron, vanadium, and uranium into soluble sulfates, and the barium and radium into bisulfates; (2) leaching of the resulting paste or solid cake with water accompanied by a separation of the coarse and fine portions of the insoluble residue; (3) extraction and recovery of the radium as crude sulfates by treating the radium concentrate with an excess of strong sulfuric acid or some other known method of extraction. The details of the process follow:

Preliminary experiments were conducted in porcelain ware with $100-g$. samples of ore in order to determine the amount of acid required and the temperature and period of digestion necessary to obtain a good extraction of radium. Subsequent experiments in cast iron kettles with charges of ore of at least I $\mathrm{kg}$., and in one experiment $50 \mathrm{lbs}$, of ore, gave the quantitative data given in Table I.

When 5 parts of low-grade ore, ground to pass through a 20 -mesh sieve, were digested with 4 parts by weight of crude sulfuric acid, $60^{\circ}$ Bé, a temperature of 250 to $300^{\circ}$, maintained from I 5 to $30 \mathrm{~min}$., was found sufficient to segregate fully 87 per cent of the radium in the finely divided portion of the insoluble residue obtained by leaching with water and differential sedimentation of the products. When the acid was reduced to I part by weight of acid to 2 parts of ore, the period of roasting had to be extended to at least half an hour and a final temperature of $300^{\circ}$ or higher was necessary in order to have the acid penetrate all parts of the ore and to secure a good ex-

I U. S. Patent 1,154,231 (1915).

${ }^{2}$ U. S. Patent $1,181,411(1916)$.

3 Schlundt, J. Phys. Chem., 20 (1916), 485. 
traction of radium. In treating the high-grade ore equal weights of acid and ore were boiled and the digestion period was extended to an hour.

The next step consisted in gradually transferring the ore-acid mass; preferably still hot, to a wooden tank containing a volume of tap water about 3 times that of the ore, and constant stirring to promote interaction and solution. The leaching with water produces precipitation of the radium-barium sulfates in very finely divided form, while the uranium and vanadium, with more or less of the other soluble compounds, pass into solution. The sands and silicates of the ore, being for the most part relatively coarsegrained, settle quite rapidly when agitation of the liquor ceases, while the finer particles, including the radium-barium sulfates, settle relatively slowly, and thus for a time constitute a suspension above the coarse sands. In fact, about a minute after the agitation of the solution ceases, a distinct boundary appears between gray sandy sediment, supernatant blue liquid and nearly white suspension.

Within 2 min. after the last stirring, the liquid with suspended matter was siphoned off or run off clear liquid was then carefully run off. The sediment or sludge remaining, when dried, constitutes the radium concentrate. Representative data selected from several experiments are incorporated under three series in Table I.

\section{TREATMENT OF THE CARNOTITE WITH SODIUM BISUL- FATE AND SALT CAKE}

The decomposition of complex radium ores by fusion with sodium bisulfate was devised by Radcliff, ${ }^{1}$ and found suitable in concentrating the radium in the refractory carnotites found in Olary, South Australia, The Australian carnotites contain rare earth and acid earth minerals not found in American carnotites. Hence, to obtain complete decomposition, Io to $\mathrm{I} 5$ per cent of sodium chloride is added to the charge of ore and sodium acid sulfate while the mass is still fluid.

In our preliminary experiments low-grade ore, ground to pass a 20 -mesh sieve, was stirred into fused sodium bisulfate in a small iron kettle heated externally. Later, larger quantities of ore were mixed with three times their weight of commercial salt cake obtained

\begin{tabular}{|c|c|c|c|c|}
\hline No. & $1 \% \mathrm{Al}$ & SERIES A & $\begin{array}{l}\text { WERLES B } \\
\text { SERLA }\end{array}$ & SERIES C \\
\hline 1 & Description of ore... & $\begin{array}{l}\text { 20-mesh, } \\
\text { Low grade }\end{array}$ & $\begin{array}{l}\text { 20-mesh, } \\
\text { Low grade }\end{array}$ & $\begin{array}{l}\text { 40-mesh, } \\
\text { High grado }\end{array}$ \\
\hline$\frac{2}{3}$ & WEIGHT USED: Ore $\ldots \ldots \ldots \ldots \ldots \ldots \ldots \ldots$ & $1720 \mathrm{~g}$ & $22.68 \mathrm{~kg}$. & $500 \mathrm{~g}$ \\
\hline 4 & Coarse sands (tailings) $\ldots \ldots \ldots \ldots \ldots \ldots \ldots$ & $13 \% 2.87$ & $\begin{array}{l}18.08 \mathrm{~kg} \\
81.9 \%\end{array}$ & $270 \mathrm{~g}$ \\
\hline $\begin{array}{l}5 \\
6\end{array}$ & $\ldots \ldots \ldots \ldots \ldots \ldots$ & $74.19 \mathrm{~g}$ & $857.69 \mathrm{~g}$ & $50.0 \mathrm{~g}$ \\
\hline$\frac{7}{8}$ & ORE DISSOLVED, & $348 \mathrm{~g}$ & $4.14 \mathrm{~kg}$ & $230 \mathrm{~g}$. \\
\hline 9 & $A C I D U$ & $1720.2 \% \mathrm{sp} . \mathrm{gr} \cdot 1.72$ & $\begin{array}{l}18.2 \% \\
21.05 \mathrm{~kg} . \mathrm{sp} . \mathrm{gr}, 1.72\end{array}$ & $\begin{aligned} & 46.0 \% \\
& 457.5 \%, \text { sp. gr. } 1.83\end{aligned}$ \\
\hline 0 & 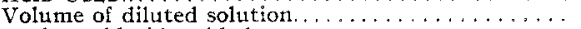 & 12 liters & 172 liters & $6920.0 \mathrm{cc}$. \\
\hline 11 & Barium chloride added $\ldots \ldots \ldots \ldots \ldots \ldots \ldots \ldots$ & $1.0 \mathrm{~g}$ & $5.0 \mathrm{~g}$ & $2.0 \mathrm{~g}$ \\
\hline $\begin{array}{l}12 \\
13\end{array}$ & Total Radium: In ore $\ldots \ldots \ldots \ldots \ldots \ldots \ldots$ & $8.39 \times 10^{-6} \mathrm{~g}$ & $11.07 \times 10^{-5} \mathrm{~g}$ & $2.118 \times 10^{-5} \mathrm{~g}$. \\
\hline 14 & In concentrate $\ldots \ldots \ldots \ldots \ldots \ldots \ldots \ldots \ldots$ & $86.5 \% \times 10^{-10} \mathrm{~g}$ & $86.8 \% \times 10 \% \mathrm{~g}$ & $79.0 \% \times 10^{-5} \mathrm{~g}$ \\
\hline $\begin{array}{l}15 \\
16\end{array}$ & In liquors $\ldots \ldots \ldots \ldots \ldots \ldots \ldots \ldots \ldots$ & $8.4 \times 10^{-8} \mathrm{~g}$ & $1.2 \times 10^{-6}$ & $1.7 \times 10^{-7} \mathrm{~g}$ \\
\hline 17 & In tailings ( $\mathrm{E}$ m. method). & $1.34 \times 10^{-6} \mathrm{~g}$. & $\cdots$ & . \\
\hline 19 & (Film method).... & $7.9 \%$ & $8.0 \%$ & $13.6 \%$ \\
\hline 20 & $\begin{array}{l}\text { PERCENTAGE EXTRACTION (E m method) } \ldots \ldots \\
\text { (Film method) } \ldots \\
\text { Radium not accounted for by film method }(a) \ldots\end{array}$ & $92.1 \%$ & $92.0 \%$ & $\begin{array}{r}86.4 \% \\
6.6 \%\end{array}$ \\
\hline & RADIUM PER GRAM: of ore $\ldots \ldots \ldots \ldots \ldots \ldots$ & $4.88 \times 10^{-9} \mathrm{~g}$ & $4.88^{2} \times 10^{-9} \mathrm{~g}$. & $4.235 \times 10^{-8} \mathrm{~g}$ \\
\hline & of concentrate $\ldots \ldots \ldots \ldots \ldots \ldots \ldots \ldots$ & $9.79 \times 10^{-8} \mathrm{~g}$. & $11.20 \times 10^{-8} \mathrm{~g}$. & $3.39 \times 10^{-7} \mathrm{~g}$ \\
\hline & Concentration tatio $\ldots \ldots \ldots$ & $20.1 \div 1$ of total & $22.9 \%$ & $8: 1$ \\
\hline & Uranium in tailings.....$\ldots \ldots \ldots \ldots \ldots \ldots$ & None & None. & $\therefore$ \\
\hline
\end{tabular}

by opening a series of stopcocks arranged at different levels in the separating tank. Naturally, to complete the removal of the finely divided material still remaining in the sands after the first treatment with water, the sands were given at least three additional washings, preferably with water containing a trace of barium chloride to prevent redissolution of a part of the radium-barium sulfate. The washed sands constituting the taiings rarely contained more than I 2 per cent of the radium in the low-grade ores.

The several wash liquors were then united and stirred vigorously for at least to min. to promote solution of the sparingly soluble calcium sulfate which formed nearly one-fifth of the suspended matter in the liquor of the first leaching with water. The total quantity of water used for leaching was approximately Io times the weight of the ore treated. The remaining suspended matter in the combined liquors was then allowed to settle 3 or 4 days in order to complete the precipitation of the radium-barium sulfates. The as a by-product in the manufacture of nitric acid. The salt cake used was found to contain 33.8 per cent of available acid which represents a product containing nearly 83 per cent as much replaceable hydrogen as in the acid sulfate, $\mathrm{NaHSO}_{4}$.

The final temperature of fusion generally exceeded $350^{\circ} \mathrm{C}$, and the mixture was kept in a fluid state for at least half an hour and stirred occasionally with an iron ladle. We did not find it necessary to add common salt to the fused charge to complete the decomposition of the ore.

When the fused mass was still hot and somewhat fluid it was slowly poured in a thin stream into 5 times its volume of water which was vigorously stirred to promote interaction and solution. When agitation ceases the coarse sands settle rapidly while the radium-barium sulfates and fine sands remain for a time suspended in the turbid liquid and their separation from the coarse sands is accomplished as pre-

$$
1 \text { U. S. Patent } 1,049,145 \text { (1912). }
$$


viously described in the treatment of the ore with concentrated sulfuric acid.

Series F, Table II, gives a typical set of experimental data obtained when low-grade ore was treated with $2^{1 / 2}$ times its weight of salt cake as described.

TABLE II-CONCENTRATION OJ RADIUM IN CARNoTITE WITH SULFUROUS

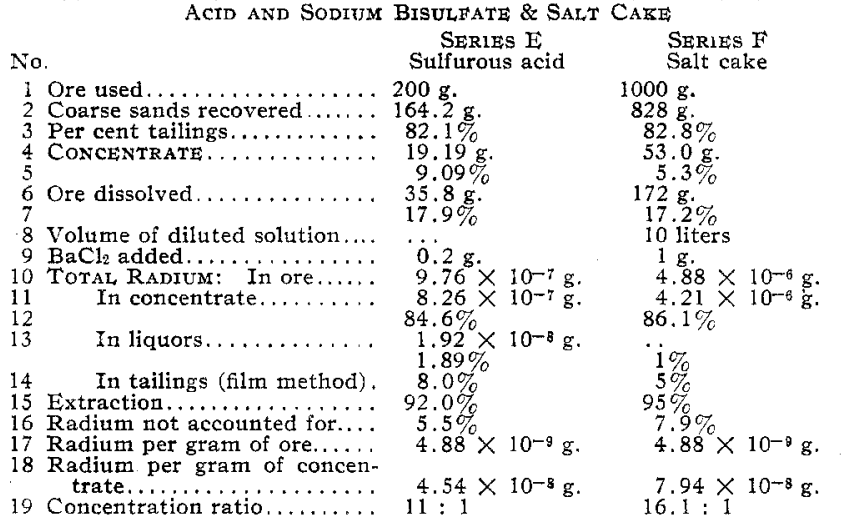

TREATMENT OF ORE WITA SULFUROUS ACID

Fleck, Haldane and White $^{1}$ suggest the direct extraction of vanadium and uranium from carnotite ores by passing sulfur dioxide into water covering the ore. Burfeind, ${ }^{2}$ in addition, describes the concentration of radium in carnotites by treating the sub. divided ore with sulfurous acid. The leaching is conducted at room temperatures and presumably at atmospheric pressure. The action of the acid may be hastened by agitation and in the course of a day or two most of the uranium and vanadium are dissolved. Shortly after agitation ceases the coarse gangue settles out and a brown amorphous mud remains for a time in suspension in the supernatant liquid. If the solution and suspended matter are drawn off about a minute or two after agitation ceases, and this operation repeated with fresh portions of dilute sulfurous acid, the radium is carried over and found for the most part in the fine sediment that finally settles out. The uranium and vanadium compounds remain dissolved in the sulfurous acid. The brown sediment constitutes the radium conceritrate. Uranium and vanadium are partially recovered by boiling off the sulfur dioxide whereupon basic sulfites of uranium and vanadium are precipitated.

Since the sulfurous acid is oxidized to some extent during digestion, some sulfates are formed, and probably for this reason the precipitation of uranium and vanadium is incomplete when the excess of sulfur dioxide is expelled.

The experimental data given under Series E, Table II, were obtained by giving $200 \mathrm{~g}$. of low-grade ore three leachings each with $400 \mathrm{cc}$. of saturated sulfurous acid at room temperatures under atmospheric pressure. In each treatment the ore and acid were left in contact for a day in a closed vessel and were well shaken up 6 to 8 times during the first I 2 hrs. of the first and second acid treatments, and then allowed to settle for I 2 hrs. The clear green liquid was then drawn off. In the third treatment the liquid and stispended

I U. S. Patent 890,584 (1908).

V. S. Patent $1,095,377(1914)$. matter were siphoned off after one minute of settling. To complete the separation of coarse and fine sands the ore residue was shaken twice with $400 \mathrm{cc}$. of water and after one minute of settling, the turbid liquid was drawn off. The coarse gangue material left in three experiments was found to contain from 7 to I 2 per cent of the radium in the ore. The sediment of fine sands that settled out from the combined leaches and wash waters after standing 4 days averaged 9 per cent of the weight of ore taken, and contained from 85 to 90 per cent of the radium. From I to 4 per cent of the radium was found in the clear solutions. By this process then the radium is concentrated approximately i t times with an extraction of nearly 87 per cent, whereas in the treatment with concentrated sulfuric acid or salt cake, the extraction is equally good while the concentration ratio is nearly 25 times for the former and $I 7$ for the latter.

\section{LEACHING OF LOW-GRADE ORE WITH CHLORINE WATER} AND CARBONIC ACID

In view of the statement by Erdman ${ }^{1}$ that small quantities of barium sulfate are not precipitated in the presence of free chlorine, it seemed worth while to ascertain whether treatment of carnotites with chlorine water results in a selective extraction of radium. Moreover, the marked solvent action of carbonated waters on compounds of the alkaline earth metals, particularly the carbonates, invited experimentation with carbonic acid.

Experiments were conducted with roo-g. samples of ore in closed vessels at room temperatures and under atmospheric pressure. Ore samples of $20 \mathrm{mesh}$ were given one treatment with $200 \mathrm{cc}$. of saturated chlorine water (or carbonic acid), respectively. The ore and liquid remained in contact for at least a day and during the first $\mathrm{I} 2 \mathrm{hrs}$. the contents of the vessels were shaken at least ro times. After settling some hours, the ore and liquid were separated by decantation and filtration. The extractions of radium obtained in these preliminary experiments ranged from I 5 to 30 per cent for the treatment with chlorine water and 30 to 40 per cent with carbonic acid. A1though these results were not very promising, further experiments are in progress with the hope of increasing the extraction by having the ore in a finer state of division and extending the period of digestion under different conditions of temperature and pressure.

\section{FURTHER TREATMENT OF RADIUM CONCENTRATE}

The radium concentrates obtained by treating the ore with sulfuric acid or salt cake as described contain from 80 to 20 parts of radium per billion. The radiumbarium sulfates constitute less than to per cent of the material, the large bulk being finely divided silica and silicates, which must be removed before refining of the crude sulfates is undertaken.

Two methods of further concentrating the radium were tried with the stock of about 2 kilos of concentrates obtained in the course of various experiments

IJ. prakt. Chem. 75 (1858), 215. 
in which the ore samples were treated with sulfuric acid and salt cake.

The first method used involved selective extraction of the sulfates of barium and radium by boiling the concentrate with concentrated sulfuric acid (sp. gr. I. 82) whereby the bisulfates are formed; these remain in solution in an excess of the hot acid and are then removed by filtration followed by washing the insoluble residue with fresh portions of hot concentrated acid. From the combined filtrates the radium and barium are precipitated by dilution with 6 to ro volumes of water containing a small quantity of barium chloride. After settling for 3 or 4 days, the diluted acid is run off and the sulfates collected on a filter. The crude sulfates thus obtained generally amounted to about ro per cent of the concentrate taken; but it should be stated that the amount of crude sulfates obtained depends to a great degree upon the porosity of the filter used in filtering the hot acid liquors. We used for filters asbestos packed in a Buchner funnel, and plates of "Filtros" $4 \mathrm{~cm}$. thick. Filtros plates of medium porosity allowed some of the fine sands to pass, thereby reducing the concentration to 4 or 5 .

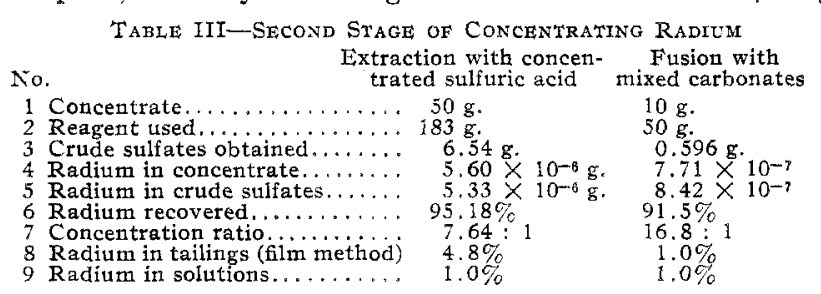

The results reported in Table III were obtained with asbestos filters and the finest grade of Filtros.

The second method of concentration tried was the customary procedure of decomposing silicates by fusion with mixed carbonates of sodium and potassium. When the fused mass was lixiviated with water, the soluble silicates were completely hydrolyzed. The insoluble residue, consisting of silica and the carbonates of radium and barium, was well washed with a I per cent solution of sodium carbonate until free from sulfates, and was then digested with dilute C. $P$. hydrochloric acid for several hours. After filtering and washing, a slight excess of sulfuric acid was added to the filtrate to precipitate the radium along with barium as sulfates. After standing for 4 days, to complete the precipitation of the sulfates, the liquid was run off and the precipitate collected on a filter. The solution of chlorides contained other bases in considerable quantity besides barium and radium, since the sulfates precipitated were found to weigh only onethird as much as the dry residue of chlorides. Typical experimental data obtained are given in Table III.

\section{SUMMARY}

I-A typical low-grade American carnotite was treated with concentrated sulfuric acid at elevated temperatures whereby radium and barium compounds are converted into bisulfates and the vanadium and uranium compounds are rendered soluble in water. From the resulting product a radium concentrate of fine sands was separated by lixiviating with a large volume of water followed by differential sedimentation. Approximately 87 per cent of the radium was thus separated and practically all of the vanadium and uranium extracted. The concentration of radium in the sediment of fine sands ranged from 20 to 28 times that of the ore.

II-Low-grade carnotite when fused with sodium bisulfate or salt cake likewise yielded a product from which a radium concentrate was separated by treatment with water accompanied by differential sedimentation. The sediment of fine sand was found to carry approximately 86 per cent of the radium of the ore and its concentration was increased from is to 20 times, depenaing to some extent upon the purity of the salt cake used. Vanadium and uranium passed into solution nearly quantitatively.

III-Digestion of low-grade carnotite with sulfurous acid at room temperatures and differential sedimentation of the products resulted in a segregation of approximately 85 per cent of the radium in the finely divided gangue material at a concentration of $r o$ to I 2 times that of the ore.

IV-The distribution of radium was determined among the solutions, concentrates, and residues obtained by the above methods of treating carnotites.

$V$-The radium in the concentrates obtained by treating the ore with sulfuric acid or salt cake was separated in the form of crude sulfates by two methods: (I) Digestion with an excess of concentrated sulfuric acid, and (2) fusion with mixed carbonates of sodium and potassium. The crude sulfates thus obtained contain fully 80 per cent of the radium of the ore, and the concentration ranges from I 50 to 300 times that of the ore.

VI-Preliminary experiments were conducted on the extraction of radium from carnotites with chlorine water and carbonic acid.

VII-The radium content of the tailings obtained in treating the ore with sulfuric acid or salt cake when determined by the emanation method was found to exceed the values obtained by comparison of the radiation from equal areas of ore and tailings. Hence it is suggested that in the approximate determination of radium in such tailings by the latter method comparisons be made against standardized samples of tailings instead of ore.

Chemical, laboratory

UNIVERSITY OF MISSOURI, COLUMBIA

\section{ERRORS IN THE DETERMINATION OF ACID VALUES OF BOILED OILS AND VARNISHES}

By E. E. WARE AND R. E. ChristMan

$$
\text { Received June 23, } 1916
$$

One of the most common analytical constants utilized in the valuation of fats, oils, and varnishes, is the neutralization or acid value. The procedure as outlined in standard texts is quite definite, although it is not ordinarily considered that any appreciable error is introduced by slight variations from recommended practice.

While it is well recognized that the regular pro-

:Holder of the Acme White Lead and Color Works Fellowship in Chemical Engineering at the University of Michigan, 1915-1916. 